\title{
Association between MTHFR C677T, MTHFR A1298C and MS A2756G polymorphisms and risk of cervical intraepithelial neoplasia II/III and cervical cancer: A meta-analysis
}

\author{
${\text { JIE } \text { ZHU }^{1 *}, \text { LEI WU }}^{2 *}$, MARTIN KOHLMEIER ${ }^{3}$, FANGLI YE $^{2}$ and WEI CAI ${ }^{1}$ \\ ${ }^{1}$ Xin Hua Hospital, Shanghai Institute for Pediatric Research, School of Medicine, Shanghai Jiaotong University, \\ Shanghai 200092; ${ }^{2}$ Medical College, Wuhan University of Science and Technology, Wuhan, \\ Hubei 430065, P.R. China; ${ }^{3}$ Nutrigenetics Laboratory, UNC Nutrition Research Institute, \\ University of North Carolina at Chapel Hill, Kannapolis, NC 28081, USA
}

Received February 14, 2013; Accepted June 17, 2013

DOI: $10.3892 / \mathrm{mmr} .2013 .1589$

\begin{abstract}
Numerous case-control studies on the association between polymorphisms of key genes involved in methionine remethylation [methylenetetrahydrofolate reductase (MTHFR) and methionine synthase (MS)] and the susceptibility of cervical intraepithelial neoplasia (CIN) and cervical cancer have provided inconclusive results. The aim of the present meta-analysis was to determine the effects of two MTHFR (C677T and A1298C) and one MS gene polymorphism (A2756G) on the risk of CIN II/III or cervical cancer. Relevant data were retrieved following a systematic search in PubMed, Web of Science, MEDLINE and Wanfang Data up to November 2012. Pooled odds ratios (ORs) with 95\% confidence intervals (CIs) were estimated from eligible studies by meta-analysis with subgroup analyses stratified by ethnicity. A total of 13 studies with 1,936 cases and 2,858 controls were included in the present meta-analysis. An increased risk of cervical cancer was found in Asian women with the MTHFR 677T allele (TT vs. $\mathrm{CC}$ : $\mathrm{OR}=1.41,95 \% \mathrm{CI}=1.07-1.86, \mathrm{P}=0.01$; TT vs. $\mathrm{CC}+\mathrm{CT}$ : $\mathrm{OR}=1.38,95 \% \mathrm{CI}=1.08-1.75, \mathrm{P}=0.008$ ), while a decreased risk was observed in Caucasian women (TT vs. CC: $\mathrm{OR}=0.65,95 \% \mathrm{CI}=0.45-0.93, \mathrm{P}=0.02$; TT+CT vs. $\mathrm{CC}: \mathrm{OR}=0.7$, 95\% CI=0.58-0.86, P=0.0005). No effects of MTHFR C677T polymorphism on CIN II/III risk and MTHFR A1298C or MS A2756G polymorphisms on cervical cancer risk were detected. The sensitivity analysis suggested stability of this
\end{abstract}

Correspondence to: Dr Jie Zhu, Xin Hua Hospital, Shanghai Institute for Pediatric Research, School of Medicine, Shanghai Jiaotong University, 1665 Kongjiang Road, Shanghai 200092, P.R. China

E-mail: jacky284868@163.com

${ }^{*}$ Contributed equally

Key words: methylenetetrahydrofolate reductase, methionine synthase, polymorphism, cervical intraepithelial neoplasia, cervical cancer meta-analysis and no publication bias was detected. The MTHFR 677T allele may enhance the risk of cervical cancer in the Asian female population and play a protective role in Caucasian females. However, limited association is suggested between MTHFR A1298C and MS A2756G polymorphisms with cervical tumorigenesis.

\section{Introduction}

Cervical cancer represents the third most common type of cancer in females worldwide with $\sim 500,000$ new cases/year. Cervical cancer leads to an estimated 274,000 deaths globally every year, resulting in an increased health and economic burden, particularly in developing countries $(1,2)$. The risk for the development of cervical cancer is enhanced through infection by human papillomavirus (HPV). However, infection with HPV alone is not sufficient for the development of this type of cancer, since several additional host factors may affect the persistence of HPV infection, which induces the malignant conversion of cervical epithelial cells (3-8). DNA hypomethylation has been shown to facilitate the integration of HPV DNA into cells and to reduce the inhibition of HPV expression (3). As a result, enzymes in the one-carbon pathway have received increasing interest since differences in metabolic properties may affect cancer risk.

Methylenetetrahydrofolate reductase (MTHFR) and methionine synthase (MS) are two important enzymes essential for nucleic acid synthesis, DNA repair and methylation; therefore, the investigation of their role in folate metabolic pathways has attracted increased interest. Two common mutations in the MTHFR gene are C677T and A1298C, and the common variant in MS is an A-to-G transversion at position 2756 (MS A2756G) (9,10). Genetic variants of MTHFR and MS genes modify the activities or other kinetic properties of the encoded enzymes (11). The functional consequences of variant enzyme properties may include abnormalities in DNA synthesis, repair and methylation, and, thereby, altered susceptibility to precancerous lesions and cervical cancer (11).

However, controversy remains concerning the role of these polymorphisms in cervical carcinogenesis in terms of 
cancer sites, racial differences and the combined influences of additional risk factors (1,11-18). To address such questions, we performed a meta-analysis of published studies to determine potential associations between MTHFR (C677T and A1298C) and MS gene polymorphisms (A2756G) with the risk of CIN II/III and cervical cancer.

\section{Materials and methods}

Search strategy and study identification. The present meta-analysis was conducted according to Meta-analysis of Observational Studies in Epidemiology (MOOSE) criteria (19). A literature search for all studies examining the association between the polymorphisms of MTHFR C677T, MTHFR A1298C and MS A2756G with CIN II/III and cervical cancer was performed using electronic databases, including PubMed, Web of Science, MEDLINE and Wanfang Data. The following keywords and subject terms were used: 'cervical intraepithelial neoplasia', 'cervical cancer', 'methylenetetrahydrofolate reductase', 'polymorphism', 'variant', 'mutation', 'folate' and 'one-carbon metabolism' up to November 30th, 2012. 'Methionine synthase' was used to replace 'methylenetetrahydrofolate reductase' in further searches of related studies. References in the identified publications were evaluated and literature retrieval was conducted in triplicate by three independent reviewers (Jie Zhu, Wei Cai and Fangli Ye).

Selection criteria. Eligible studies were included in the present meta-analysis when the following criteria were met: i) the study was an unrelated case-control study examining the association between MTHFR or MS gene polymorphisms and CIN II/III or cervical cancer; ii) the sample size, distribution of genotype frequency or additional information was available; iii) the genotype distribution of the population met all the expectation of the Hardy-Weinberg equilibrium (HWE) theory; iv) for studies where the same or overlapping data were used, the most recent study was included in the present meta-analysis; and v) only studies published as full length articles or letters with adequate study details were used.

Data extraction. Data were collected for meta-analysis according to the selection criteria. The collected information included the year of publication, country, ethnicity, mean age of study population, study design, study method, sample size, source of controls, as well as allele and genotype frequencies in case and control groups.

Statistical analysis. Deviation from HWE was determined by Fisher's exact test in the control group of each study. Crude odds ratios (ORs) with their $95 \%$ confidence intervals (CIs) were applied to evaluate the strength of association of MTHFR C677T, MTHFR A1298C and MS A2756G polymorphisms with CIN II/III or cervical cancer, respectively. The pooled ORs and their $95 \%$ CIs were calculated and compared for different genetic models for MTHFR C677T allele T [allele model (T vs. C), homozygote model (TT vs. CC), dominant model (TT+CT vs. $\mathrm{CC}$ ) and recessive model (TT vs. $\mathrm{CT}+\mathrm{CC}$ )]. The same comparisons were performed for allele C of the MTHFR A1298C and allele $\mathrm{G}$ of the MS A2756G polymorphism, respectively.
A Chi-square-based Q-test was conducted to assess heterogeneity between studies, which was considered significant when $\mathrm{P}<0.05$. The percentage variability of the overall OR attributable to heterogeneity between studies was assessed by $\mathrm{I}^{2}$ test. A fixed effects model was used to calculate the summary OR value when heterogeneity did not exist (20). Otherwise, a random effects model (Mantel-Haenszel method) was adopted (20). A Z-test was implemented to determine the significance of the pooled $\mathrm{OR}$ and $\mathrm{P}<0.05$ was considered to indicate a statistically significant difference. In order to estimate ethnic-specific OR, subgroup analyses were also performed for Asian and Caucasian populations, respectively. The MTHFR A1298C and MS A2756G comparisons for the association with CIN II/III were not stratified for subgroup analysis due to the limitations of the available data. Sensitivity analyses were conducted by reassessing the significance of ORs after each study was omitted in turn. Publication bias was examined with Egger's linear regression test and Begg's funnel plot test.

All statistical analyses were performed using the program Review Manager 5 and STATA software package (version 11.0; StataCorp, College Station, TX, USA). All the P-values were two-sided and $\mathrm{P}<0.05$ for any test or model was considered to indicate a statistically significant difference.

\section{Results}

Selection of eligible studies. Concerning cervical cancer, 22 studies were retrieved for cervical cancer and 13 met our inclusion criteria; 8 studies were excluded since detailed genotyping information was not available. Moreover, 1 study (8) was replaced with its updated version since the subjects in these 2 studies were from the same population. The final pool of eligible studies consisted of 13 studies with 1,936 cases and 2,858 controls $(3,6,12,13,15,17,21-27)$ for MTHFR C677T polymorphism (Table I), 5 studies with 585 cases and 1,000 controls for MTHFR A1298C polymorphism (Table I), and 3 studies with 389 cases and 440 controls for MS A2756G polymorphism (Table I). The genotype distribution in the controls of all these studies was consistent with HWE. However, not all the studies provided enough data for the ethnicity subgroup analysis of the association of MTHFR A1298C or MS A2756G polymorphism with the risk to cervical cancer.

With regard to CIN II/III, 8 studies were retrieved and 8 were included in the present meta-analysis according to the selection criteria. One study (8) was replaced with its updated version due to overlapping inclusion of study subjects in the most recent study. The eligible studies comprised 7 studies $(3,6,17,21,24,26,27)$ with 1,936 cases and 2,858 controls for MTHFR C677T polymorphism (Table I) and the genotype distribution in the controls of all these studies was consistent with HWE. There were not enough studies available for the meta-analysis of the contribution of MTHFR A1298C or MS A2756G polymorphisms to susceptibility to CIN II/III.

DNA was prepared from blood samples or tissue for genotyping in all the studies. SNaPshot genotyping assay was adopted in 2 studies $(3,21)$ and a TaqMan single nucleotide polymorphism (SNP) genotyping assay was used in 2 studies $(6,17)$ with polymerase chain reaction-restriction fragment length polymorphism (PCR-RFLP) employed in all 
Table I. Characteristics of eligible studies included in this meta-analysis.

\begin{tabular}{|c|c|c|c|c|c|c|}
\hline Study & $\begin{array}{c}\text { Year of } \\
\text { publication }\end{array}$ & Ethnicity & $\begin{array}{c}\text { Mean age } \\
\text { (Case/control) }\end{array}$ & Genotyping method & Source of controls & Ref. \\
\hline Goodman et al & 2001 & Mixed & $\mathrm{NS} / \mathrm{NS}$ & PCR-RFLP & $\begin{array}{l}\text { Hospital-based, } \\
\text { case-control study }\end{array}$ & (13) \\
\hline Lambropoulos et al & 2003 & Caucasian & $33.2 / 33.2$ & PCR-RFLP & $\begin{array}{l}\text { Hospital-based, } \\
\text { case-control study }\end{array}$ & (24) \\
\hline Sull et al & 2004 & Asian & $50.3 / 46.2$ & SNaPshot & $\begin{array}{l}\text { Population-based, } \\
\text { case-control study }\end{array}$ & $(21)$ \\
\hline Kang et al & 2005 & Asian & $\mathrm{NS} / \mathrm{NS}$ & PCR-RFLP & $\begin{array}{l}\text { Hospital-based, } \\
\text { case-control study }\end{array}$ & $(15)$ \\
\hline Zoodsma et al & 2005 & Caucasian & $\mathrm{NS} / \mathrm{NS}$ & TaqMan SNP & $\begin{array}{l}\text { Hospital-based, } \\
\text { case-control study }\end{array}$ & (17) \\
\hline Delgado-Enciso et al & 2006 & Mixed & $46 / 44$ & PCR-RFLP & $\begin{array}{l}\text { Hospital-based, } \\
\text { case-control study }\end{array}$ & $(25)$ \\
\hline Wang et al & 2006 & Asian & $52.53 / 50.56$ & PCR-RFLP & $\begin{array}{l}\text { Hospital-based, } \\
\text { case-control study }\end{array}$ & $(27)$ \\
\hline Piyathilake et al & 2007 & Mixed & $21.5 / 23.0$ & PCR-RFLP & $\begin{array}{l}\text { Hospital-based, } \\
\text { case-control study }\end{array}$ & (26) \\
\hline Shekari et al & 2008 & Asian & $48.55 / 48.81$ & PCR-RFLP & $\begin{array}{l}\text { Hospital-based, } \\
\text { case-control study }\end{array}$ & $(22)$ \\
\hline Kohaar et al & 2010 & Asian & $49.4 / 48.2$ & SNaPshot & $\begin{array}{l}\text { Hospital-based, } \\
\text { case-control study }\end{array}$ & (3) \\
\hline Tong et al & 2011 & Asian & $50.8 / 45.7$ & TaqMan SNP & $\begin{array}{l}\text { Hospital-based, } \\
\text { case-control study }\end{array}$ & (6) \\
\hline Prasad and Wilkhoo & 2011 & Asian & $\mathrm{NS} / \mathrm{NS}$ & PCR-RFLP & $\begin{array}{l}\text { Population-based, } \\
\text { case-control study }\end{array}$ & (12) \\
\hline Mostowska et al & 2011 & Caucasian & $54.6 / 53.3$ & PCR-RFLP & $\begin{array}{l}\text { Hospital-based, } \\
\text { case-control study }\end{array}$ & (23) \\
\hline
\end{tabular}

NS, not stated; PCR-RFLP, polymerase chain reaction-restriction fragment length polymorphism; SNP, single nucleotide polymorphism.

of the remaining studies $(13,15,22-27)$ to validate genotype distribution (Table I).

Results of the meta-analysis. Genotype distributions, allele frequencies, summary ORs and 95\% CI for various genetic contrasts investigating the association of MTHFR C677T and A1298C or MS A2756G polymorphisms with cervical cancer and CIN II/III are listed in Tables II-V.

With respect to the MTHFR C677T polymorphism, no association was found with cervical cancer when a random effects model was adopted to conduct a worldwide allele comparison $(\mathrm{T}$ vs. $\mathrm{C}$ : $\mathrm{P}=0.53, \mathrm{OR}=0.94,95 \% \mathrm{CI}=0.78-1.14$, $\mathrm{P}=0.007$ for heterogeneity; Table $\mathrm{V}$ ). In the ethnicity subgroup analysis, an enhanced risk was demonstrated in Asian women (TT vs. CC: $\mathrm{P}=0.01, \mathrm{OR}=1.41,95 \% \mathrm{CI}=1.07-1.86, \mathrm{P}=0.05$ for heterogeneity; Table V and Fig. 1A). By contrast, an inverse association was observed in Caucasian women (TT vs. CC: $\mathrm{P}=0.02, \mathrm{OR}=0.65,95 \% \mathrm{CI}=0.45-0.93, \mathrm{P}=0.99$ for heteroge neity; Table V and Fig. 1B). Furthermore, meta-analyses of the contrasts in a recessive genetic model revealed that the $677 \mathrm{~T}$ allele is more likely to reduce the risk of Caucasian women (TT+CT vs. $\mathrm{CC}: \mathrm{P}=0.0005, \mathrm{OR}=0.7,95 \% \mathrm{CI}=0.58-0.86$, $\mathrm{P}=0.66$ for heterogeneity; Table V and Fig. 1C), while the $677 \mathrm{~T}$ allele is more likely to increase the risk of Asian women (TT vs. $\mathrm{CC}+\mathrm{CT}$ : $\mathrm{P}=0.008, \mathrm{OR}=1.38,95 \% \mathrm{CI}=1.08-1.75, \mathrm{P}=0.12$ for heterogeneity; Table $\mathrm{V}$ and Fig. 1D). No significant effect of MTHFR A1298C polymorphism on the susceptibility was found in worldwide populations ( $\mathrm{C}$ vs. $\mathrm{A}: \mathrm{P}=0.94, \mathrm{OR}=0.99$, 95\% $\mathrm{CI}=0.82-1.20, \mathrm{P}=0.83$ for heterogeneity) and in Asian females (C vs. A: $\mathrm{P}=0.59$, $\mathrm{OR}=1.06,95 \% \mathrm{CI}=0.85-1.33, \mathrm{P}=0.96$ for heterogeneity; Table V). Similarly, no association between MS A2756G polymorphism and cervical cancer was detected in the worldwide population ( $\mathrm{G}$ vs. $\mathrm{A}$ : $\mathrm{P}=0.002, \mathrm{OR}=0.65$, 95\% CI=0.21-1.98, $\mathrm{P}=0.0001$ for heterogeneity; Table V).

Withrespect toassociation with CINII/III, meta-analyses did not provide evidence to support an association between $\mathrm{C} 677 \mathrm{~T}$ polymorphism and susceptibility to CIN II/III in the worldwide population (T vs. $\mathrm{C}: \mathrm{P}=0.86, \mathrm{OR}=1.01,95 \% \mathrm{CI}=0.88-1.17$, $\mathrm{P}=0.8$ for heterogeneity; Table $\mathrm{V}$ ) and in Asian women ( $\mathrm{T}$ vs. $\mathrm{C}: \mathrm{P}=0.49, \mathrm{OR}=1.07,95 \% \mathrm{CI}=0.88-1.31, \mathrm{P}=0.86$ for heterogeneity; Table V).

Sensitivity analysis. Sensitivity analysis was conducted by sequentially omitting each study in turn under homozygote and recessive contrasts performed on a worldwide population and on ethnically defined subgroups to evaluate the robustness and 
Table II. Distribution of MTHFR C677T genotypes and their allelic frequency associated with the risk of cervical cancer or CIN II/III.

\begin{tabular}{|c|c|c|c|c|c|c|c|c|}
\hline \multirow[b]{2}{*}{ Study } & \multicolumn{5}{|c|}{ Genotype distribution, $\mathrm{n}$} & \multirow[b]{2}{*}{ Chi-square } & \multirow{2}{*}{$\begin{array}{l}\text { HWE P-value } \\
\text { (control) }\end{array}$} & \multirow[b]{2}{*}{ Ref. } \\
\hline & & Total & $\mathrm{CC}$ & $\mathrm{CT}$ & TT & & & \\
\hline \multicolumn{9}{|l|}{ Cervical cancer } \\
\hline \multirow[t]{2}{*}{ Lambropoulos et al } & Case & 21 & 11 & 8 & 2 & 0.699 & 0.403 & (24) \\
\hline & Control & 91 & 42 & 37 & 12 & & & \\
\hline \multirow[t]{2}{*}{ Sull et al } & Case & 246 & 73 & 115 & 58 & 0 & 0.990 & $(21)$ \\
\hline & Control & 454 & 153 & 221 & 80 & & & \\
\hline \multirow[t]{2}{*}{ Kang et al } & Case & 79 & 27 & 32 & 20 & 0.482 & 0.487 & $(15)$ \\
\hline & Control & 74 & 30 & 32 & 12 & & & \\
\hline \multirow[t]{2}{*}{ Zoodsma et al } & Case & 636 & 357 & 230 & 49 & 0.263 & 0.608 & (17) \\
\hline & Control & 592 & 273 & 262 & 57 & & & \\
\hline \multirow[t]{2}{*}{ Wang et al } & Case & 111 & 20 & 53 & 38 & 1.137 & 0.286 & (27) \\
\hline & Control & 111 & 33 & 60 & 18 & & & \\
\hline \multirow[t]{2}{*}{ Delgado-Enciso et al } & Case & 70 & 18 & 34 & 18 & 0.910 & 0.340 & $(25)$ \\
\hline & Control & 89 & 20 & 49 & 20 & & & \\
\hline \multirow[t]{2}{*}{ Shekari et al } & Case & 200 & 170 & 28 & 2 & 0.372 & 0.542 & $(22)$ \\
\hline & Control & 200 & 125 & 68 & 7 & & & \\
\hline \multirow[t]{2}{*}{ Kohaar et al } & Case & 164 & 113 & 47 & 4 & 0.277 & 0.599 & (3) \\
\hline & Control & 231 & 161 & 65 & 5 & & & \\
\hline \multirow[t]{2}{*}{ Tong et al } & Case & 146 & 53 & 65 & 28 & 0.792 & 0.373 & (6) \\
\hline & Control & 427 & 152 & 198 & 77 & & & \\
\hline \multirow[t]{2}{*}{ Prasad and Wilkhoo } & Case & 62 & 0 & 5 & 57 & 3.472 & 0.062 & (12) \\
\hline & Control & 125 & 1 & 8 & 116 & & & \\
\hline \multirow[t]{2}{*}{ Mostowska et al } & Case & 124 & 56 & 59 & 9 & 0.649 & 0.420 & (23) \\
\hline & Control & 168 & 69 & 81 & 18 & & & \\
\hline \multicolumn{9}{|l|}{ CIN II/III } \\
\hline \multirow[t]{2}{*}{ Goodman et al } & Case & 150 & 73 & 67 & 10 & 0.656 & 0.418 & (13) \\
\hline & Control & 179 & 93 & 75 & 11 & & & \\
\hline \multirow[t]{2}{*}{ Lambropoulos et al } & Case & 64 & 27 & 29 & 8 & 0.622 & 0.430 & $(24)$ \\
\hline & Control & 91 & 42 & 37 & 12 & & & \\
\hline \multirow[t]{2}{*}{ Sull et al } & Case & 176 & 50 & 90 & 36 & 0 & 0.990 & $(21)$ \\
\hline & Control & 454 & 153 & 221 & 80 & & & \\
\hline \multirow[t]{2}{*}{ Zoodsma et al } & Case & 264 & 121 & 120 & 23 & 0.340 & 0.556 & (17) \\
\hline & Control & 592 & 273 & 262 & 57 & & & \\
\hline \multirow[t]{2}{*}{ Piyathilake et al } & Case & 80 & 59 & 16 & 5 & 0.034 & 0.853 & (26) \\
\hline & Control & 355 & 223 & 116 & 16 & & & \\
\hline \multirow[t]{2}{*}{ Kohaar et al } & Case & 39 & 28 & 11 & 0 & 0.277 & 0.599 & (3) \\
\hline & Control & 231 & 161 & 65 & 5 & & & \\
\hline \multirow[t]{2}{*}{ Tong et al } & Case & 160 & 54 & 74 & 32 & 0.792 & 0.373 & (6) \\
\hline & Control & 427 & 152 & 198 & 77 & & & \\
\hline
\end{tabular}

CIN, cervical intraepithelial neoplasia; HWE, Hardy-Weinberg equilibrium; MTHFR, methylenetetrahydrofolate reductase.

plausibility of the meta-analysis. The pooled ORs (including 95\% CI) from various contrasts were not significantly altered (data not shown), indicating that the summary estimate of the effect of MTHFR C677T, MTHFR A1298C and MS A2756G polymorphisms on the risk of cervical cancer and CIN II/III was not altered during the sensitivity analysis.

Publication bias. The Begg's funnel plot and Egger's test were conducted to estimate the publication bias of the included studies. The funnel plot for the comparison of the $677 \mathrm{C}$ allele with the $677 \mathrm{~T}$ allele provided limited evidence on obvious asymmetry. No publication bias by Egger's test was detected for the comparison in homozygote (TT vs. CC), dominant ( TT+CT vs. CC) and recessive models (TT vs. CT+CC) for both cervical cancer and CIN II/III (Table VI). Similarly, there was no statistical evidence suggesting publication bias for the comparison of the three models of MTHFR A1298C polymorphism for cervical cancer (Table VI). Furthermore, no 
Table III. Distribution of MTHFR A1298C genotypes and their allelic frequency associated with the risk of cervical cancer.

\begin{tabular}{|c|c|c|c|c|c|c|c|c|}
\hline \multirow[b]{2}{*}{ Study } & \multicolumn{5}{|c|}{ Genotype distribution, $\mathrm{n}$} & \multirow[b]{2}{*}{ Chi-square } & \multirow{2}{*}{$\begin{array}{l}\text { HWE P-value } \\
\text { (control) }\end{array}$} & \multirow[b]{2}{*}{ Ref. } \\
\hline & & Total & $\mathrm{CC}$ & $\mathrm{CT}$ & TT & & & \\
\hline \multirow[t]{2}{*}{ Kang et al } & Case & 79 & 55 & 22 & 2 & \multirow[t]{2}{*}{0.895} & \multirow[t]{2}{*}{0.344} & \multirow[t]{2}{*}{$(15)$} \\
\hline & Control & 84 & 58 & 25 & 1 & & & \\
\hline \multirow[t]{2}{*}{ Delgado-Enciso et al } & Case & 70 & 2 & 24 & 44 & \multirow[t]{2}{*}{0.002} & \multirow[t]{2}{*}{0.969} & \multirow[t]{2}{*}{$(25)$} \\
\hline & Control & 89 & 2 & 23 & 64 & & & \\
\hline \multirow[t]{2}{*}{ Kohaar et al } & Case & 164 & 58 & 83 & 23 & \multirow[t]{2}{*}{2.293} & \multirow[t]{2}{*}{0.123} & \multirow[t]{2}{*}{ (3) } \\
\hline & Control & 231 & 85 & 119 & 27 & & & \\
\hline \multirow[t]{2}{*}{ Tong et al } & Case & 148 & 89 & 57 & 2 & \multirow[t]{2}{*}{0.215} & \multirow[t]{2}{*}{0.643} & \multirow[t]{2}{*}{$(6)$} \\
\hline & Control & 428 & 278 & 132 & 18 & & & \\
\hline \multirow[t]{2}{*}{ Mostowska et al } & Case & 124 & 56 & 59 & 9 & \multirow[t]{2}{*}{0.649} & \multirow[t]{2}{*}{0.420} & \multirow[t]{2}{*}{$(23)$} \\
\hline & Control & 168 & 69 & 81 & 18 & & & \\
\hline
\end{tabular}

HWE, Hardy-Weinberg equilibrium; MTHFR, methylenetetrahydrofolate reductase.

Table IV. Distribution of MS A2756G genotypes and their allelic frequency associated with the risk of cervical cancer.

\begin{tabular}{|c|c|c|c|c|c|c|c|c|}
\hline \multirow[b]{2}{*}{ Study } & \multicolumn{5}{|c|}{ Genotype distribution, $\mathrm{n}$} & \multirow[b]{2}{*}{ Chi-square } & \multirow{2}{*}{$\begin{array}{l}\text { HWE P-value } \\
\text { (control) }\end{array}$} & \multirow[b]{2}{*}{ Ref. } \\
\hline & & Total & $\mathrm{CC}$ & CT & $\mathrm{TT}$ & & & \\
\hline \multirow[t]{2}{*}{ Kang et al } & Case & 65 & 53 & 10 & 2 & 0.835 & 0.361 & $(15)$ \\
\hline & Control & 72 & 58 & 14 & 0 & & & \\
\hline \multirow[t]{2}{*}{ Shekari et al } & Case & 200 & 181 & 14 & 5 & 1.834 & 0.176 & $(22)$ \\
\hline & Control & 200 & 118 & 63 & 14 & & & \\
\hline \multirow[t]{2}{*}{ Mostowska et al } & Case & 124 & 72 & 44 & 8 & 1.900 & 0.168 & $(23)$ \\
\hline & Control & 168 & 109 & 49 & 10 & & & \\
\hline
\end{tabular}

HWE, Hardy-Weinberg equilibrium.

publication bias was observed for the $\mathrm{G}$ vs. A allele contrast of MS A2756G polymorphism for cervical cancer $(t=0.61$, $\mathrm{P}=0.654)$.

\section{Discussion}

Cervical cancer is one of the three major malignancies found in female cancer patients worldwide, accounting for 250,000 deaths/year, with higher incidences being observed in developing countries compared with developed countries $(17,26,28)$. Therefore, it would be useful to have precise susceptibility information on cervical carcinogenesis to develop effective, specific and individualized disease prevention programs for different populations $(37,38)$.

Infection with oncogenic subtypes of HPV has been confirmed to play a crucial etiological role in the development of cervical cancer $(32,38,39)$. However, infection with high-risk HPV alone is not sufficient to cause cervical neoplasia. An increasing number of studies suggest that oral contraceptives, smoking, host genetic factors and epigenetic changes enhance susceptibility to the development of cervical intraepithelial neoplasia and invasive cancer $(23,30)$. Recently, epidemiological studies have reported that heritable factors, including genetic polymorphisms, contributed to $\sim 64 \%$ of the familial risks for cervical cancer $(23,30)$.

Variation of several candidate genes involved in the one-carbon metabolism pathway may explain some of the individual differences in cervical tumorigenesis, including MTR, BHMT, MTHFR, MTHFD1 and MS, among which MTHFR and MS are two of the most commonly investigated candidate genes.

MTHFR catalyzes the conversion of 5,10-methylenetetrahydrofolate (5,10-methylene-THF) to 5-methyltetrahydrofolate (5-methyl-THF). 5,10-methylene-THF is a substrate necessary for thymidine synthesis, while 5-methyl-THF acts as a substrate for the remethylation of homocysteine under the catalysis of MS, resulting in methionine synthesis, which plays a role as a substrate for S-adenosyl methionine (SAM) synthesis. SAM is a universal methyl donor necessary for DNA and protein methylation. Increased MTHFR function results in low levels of 5,10-methylene-THF, thereby leading to the misincorporation of dUTP into DNA, which in turn causes double strand breaks $(9,31)$. Conversely, decreased MTHFR activity may result in low levels of 5-methyl-THF and, thus, be responsible for DNA hypomethylation. These are common features in cancer development $(9,21,23,24)$. 
Table V. Meta-analysis of various genetic comparisons investigating the association of MTHFR C677T, MTHFR A1298C and MS A2756G polymorphisms with cervical cancer or CIN II/III susceptibility.

\begin{tabular}{|c|c|c|c|c|c|}
\hline Analysis model & Ethnicity & $\begin{array}{l}\text { Random effects model } \\
\quad \text { OR }(95 \% \mathrm{CI})\end{array}$ & $\begin{array}{c}\text { Fixed effects model } \\
\text { OR }(95 \% \text { CI })\end{array}$ & $\begin{array}{c}\text { P-value for } \\
\text { heterogeneity }\end{array}$ & $\begin{array}{c}\text { P-value for } \\
\text { fixed effects model }\end{array}$ \\
\hline \multicolumn{6}{|l|}{$\begin{array}{l}\text { MTHFR C677T } \\
\text { in cervical cancer }\end{array}$} \\
\hline \multirow[t]{3}{*}{ T vs. C } & Asian & $0.98(0.73-1.32)$ & $1.01(0.87-1.17)$ & 0.002 & 0.93 \\
\hline & Caucasian & $0.82(0.69-0.97)$ & $0.82(0.69-0.97)$ & 0.87 & 0.02 \\
\hline & Total & $0.94(0.78-1.14)$ & $0.93(0.83-1.103)$ & 0.007 & 0.17 \\
\hline \multirow[t]{3}{*}{ TT vs. CC } & Asian & $1.4(0.87-2.26)$ & $1.41(1.07-1.86)$ & 0.05 & 0.01 \\
\hline & Caucasian & $0.65(0.45-0.93)$ & $0.65(0.45-0.93)$ & 0.99 & 0.02 \\
\hline & Total & $1.07(0.73-1.58)$ & $1.06(0.86-1.31)$ & 0.008 & 0.6 \\
\hline \multirow[t]{3}{*}{$\mathrm{TT}+\mathrm{CT}$ vs. $\mathrm{CC}$} & Asian & $0.98(0.62-1.54)$ & $0.94(0.79-1.13)$ & $<0.0001$ & 0.52 \\
\hline & Caucasian & $0.7(0.58-0.86)$ & $0.7(0.58-0.86)$ & 0.66 & 0.0005 \\
\hline & Total & $0.89(0.66-1.18)$ & $0.83(0.73-0.94)$ & $<0.0001$ & 0.004 \\
\hline \multirow[t]{3}{*}{ TT vs. $\mathrm{CC}+\mathrm{CT}$} & Asian & $1.36(0.95-1.95)$ & $1.38(1.08-1.75)$ & 0.12 & 0.008 \\
\hline & Caucasian & $0.75(0.53-1.07)$ & $0.75(0.53-1.07)$ & 0.92 & 0.11 \\
\hline & Total & $1.13(0.84-1.52)$ & $1.14(0.94-1.38)$ & 0.05 & 0.18 \\
\hline \multicolumn{6}{|l|}{$\begin{array}{l}\text { MTHFR C677T } \\
\text { in CIN II/III }\end{array}$} \\
\hline \multirow[t]{2}{*}{ T vs. C } & Total & $1.01(0.88-1.17)$ & $1.01(0.88-1.17)$ & 0.8 & 0.86 \\
\hline & Asian & $1.00(0.67-1.48)$ & $1.07(0.88-1.31)$ & 0.86 & 0.49 \\
\hline \multirow[t]{2}{*}{ TT vs. CC } & Total & $1.13(0.86-1.49)$ & $1.12(0.86-1.48)$ & 0.91 & 0.4 \\
\hline & Asian & $1.25(0.88-1.80)$ & $1.25(0.87-1.78)$ & 0.76 & 0.22 \\
\hline \multirow[t]{2}{*}{ TT+CT vs. CC } & Total & $1.02(0.85-1.23)$ & $1.02(0.86-1.22)$ & 0.37 & 0.79 \\
\hline & Asian & $1.14(0.89-1.48)$ & $1.14(0.89-1.47)$ & 0.67 & 0.3 \\
\hline \multirow[t]{2}{*}{ TT vs. $\mathrm{CC}+\mathrm{CT}$} & Total & $1.09(0.85-1.39)$ & $1.08(0.84-1.39)$ & 0.93 & 0.54 \\
\hline & Asian & $1.16(0.85-1.59)$ & $1.16(0.84-1.58)$ & 0.85 & 0.37 \\
\hline \multicolumn{6}{|l|}{$\begin{array}{l}\text { MTHFR A1298C } \\
\text { in cervical cancer }\end{array}$} \\
\hline \multirow[t]{2}{*}{ C vs. A } & Total & $0.99(0.82-1.20)$ & $0.99(0.82-1.20)$ & 0.83 & 0.94 \\
\hline & Asian & $1.06(0.85-1.33)$ & $1.06(0.85-1.33)$ & 0.96 & 0.59 \\
\hline \multirow[t]{2}{*}{ CC vs. AA } & Total & $0.89(0.55-1.41)$ & $0.85(0.54-1.34)$ & 0.43 & 0.48 \\
\hline & Asian & $0.96(0.40-2.27)$ & $0.99(0.57-1.71)$ & 0.25 & 0.96 \\
\hline \multirow{2}{*}{$\mathrm{CC}+\mathrm{AC}$ vs. $\mathrm{AA}$} & Total & $1.05(0.83-1.31)$ & $1.04(0.83-1.31)$ & 0.81 & 0.7 \\
\hline & Asian & $1.12(0.86-1.45)$ & $1.12(0.86-1.45)$ & 0.8 & 0.39 \\
\hline \multirow{2}{*}{$\mathrm{CC}$ vs. $\mathrm{AA}+\mathrm{AC}$} & Total & $0.81(0.52-1.24)$ & $0.80(0.56-1.16)$ & 0.31 & 0.24 \\
\hline & Asian & $0.91(0.35-2.38)$ & $0.98(0.58-1.63)$ & 0.19 & 0.93 \\
\hline \multicolumn{6}{|l|}{$\begin{array}{l}\text { MS A2756G in } \\
\text { cervical cancer }\end{array}$} \\
\hline G vs. A & Total & $0.65(0.21-1.98)$ & $0.62(0.46-0.84)$ & 0.0001 & 0.002 \\
\hline GG vs. AA & Total & $0.79(0.17-3.62)$ & $0.64(0.33-1.21)$ & 0.03 & 0.17 \\
\hline GG+AG vs. AA & Total & $0.63(0.26-1.50)$ & $0.61(0.47-0.79)$ & 0.0001 & 0.002 \\
\hline GG vs. $A A+A G$ & Total & $0.81(0.25-2.62)$ & $0.72(0.38-1.38)$ & 0.11 & 0.32 \\
\hline
\end{tabular}

CIN, cervical intraepithelial neoplasia; OR, odds ratio; CI, confidence interval; MTHFR, methylenetetrahydrofolate reductase.

The gene for MTHFR is located on chromosome $1 \mathrm{p} 36$ with 11 exons (44) and SNPs within the coding region are associated with DNA hypomethylation, which constitutes a hallmark of human cancer cells $(1,24,25)$. Two common mutations in the MTHFR gene are C677T and A1298C. MTHFR C677T polymorphism leads to substitution of alanine by valine at the amino acid position 222, which affects the catalytic domain of the enzyme and decreases its affinity for its cofactor (9). This altered form of enzyme results in a thermolabile protein and is associated with reduced enzymatic activity $(9,10)$. Thus, elevated homocysteine levels may be attributed to a correspondingly decreased activity of this enzyme in individuals homozygous and heterozygous for the variation (9), which results in abnormalities in DNA methylation (23). MTHFR 
A

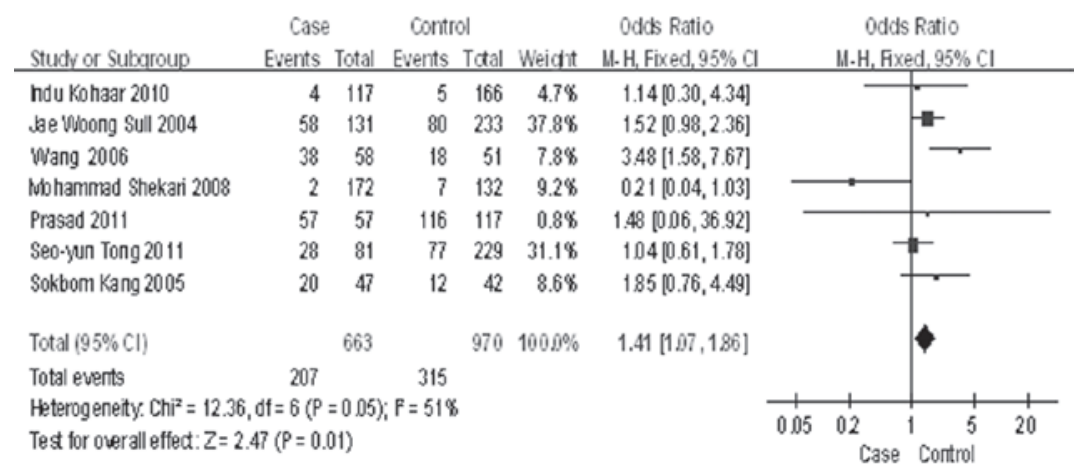

B

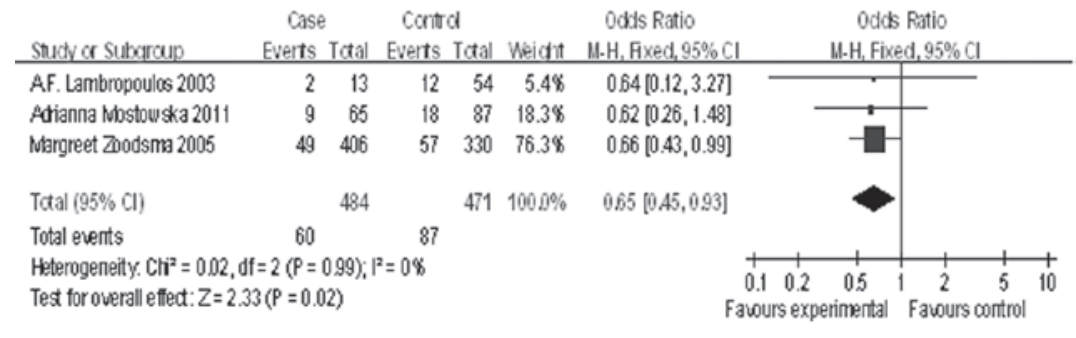

$\mathbf{C}$

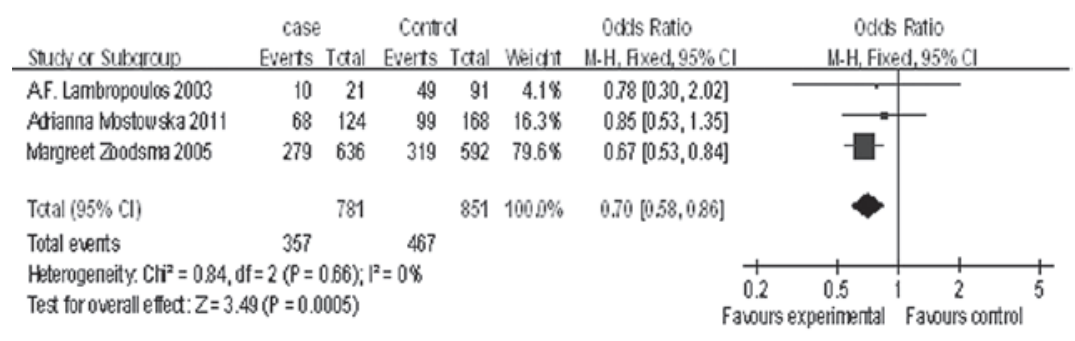

D

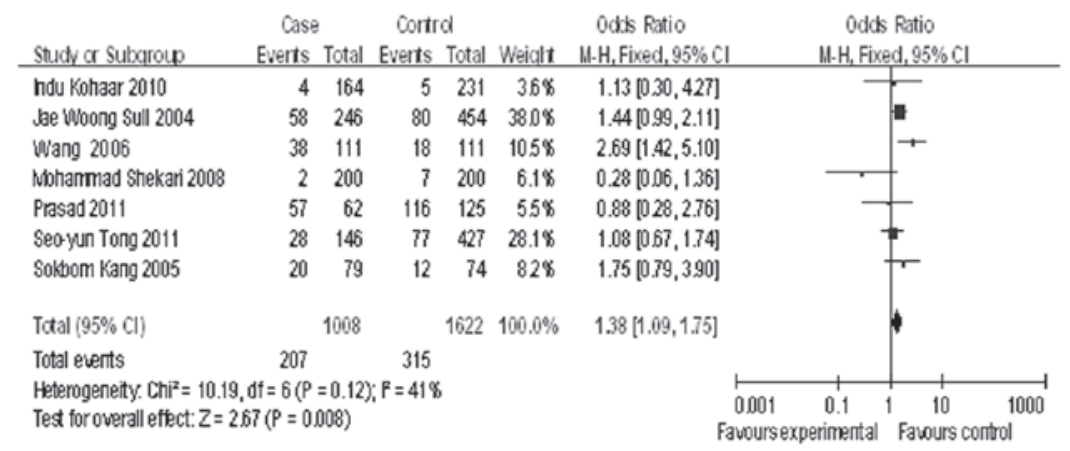

Figure 1. Meta-analysis for the association between MTHFR C677T polymorphism and cervical cancer susceptibility stratified by ethnicity. Point estimates of the OR together with $95 \%$ CI values for each study obtained with a fixed effects model are plotted. (A) Analysis of cervical cancer risk for TT genotype when compared with the $\mathrm{CC}$ genotype in the Asian population. (B) Analysis of cervical cancer risk for TT genotype when compared with the CC genotype in the Caucasian population. (C) Analysis of the comparison in TT + CT vs. CC in the Caucasian population. (D) Analysis of the comparison in TT vs. CC+CT in the Asian population. OR, odds ratio; CI, confidence interval; MTHFR, methylenetetrahydrofolate reductase.

A1298C polymorphism converts a glutamine to alanine at the amino acid position 429 (9), which is located within the regulatory domain of this protein (9). However, this alteration does not appear to affect the function of MTHFR by itself, but may reduce MTHFR activity when it is heterozygous with the $1556 \mathrm{G} \rightarrow \mathrm{A}, 1743 \mathrm{G} \rightarrow \mathrm{A}$ and $1958 \mathrm{C} \rightarrow \mathrm{T}$ polymorphisms $(9,34,35)$.

Due to both MS and MTHFR functioning in the same metabolic pathway sequentially, the affect of MS gene polymorphism constitutes an additional interesting research issue. MS catalyzes the methyl transfer from homocysteine to methionine with cobalamine as a co-factor to maintain adequate intracellular SAM levels for DNA methylation, which is believed to suppress cancer development. The common variant in $\mathrm{MS}$ is an A-to-G transversion at position
2756 (MS A2756G), which leads to the replacement of aspartate by glycine, resulting in altered enzyme activity and, thus, affecting DNA methylation (1,35).

There is an increasing number of studies demonstrating that MTHFR and MS polymorphisms play different roles in influencing susceptibility to breast, colorectal, pancreatic, hepatocellular and prostate cancers. Particularly, the effect of MTHFR and MS polymorphisms on the risk of CIN II/III and cervical cancer also remains inconsistent (12,15-20). The MTHFR C677T gene variant has been associated with a risk of cervical carcinogenesis in certain cohorts $(13,17,21,23)$, while this MTHFR gene variant has been associated with protection against CIN II/III or cervical cancer (15), or has not been confirmed as a risk factor for this type of cancer in 
Table VI. Publication bias detection for MTHFR C677T and MTHFR A1298C polymorphisms.

\begin{tabular}{|c|c|c|c|c|c|}
\hline Genetic type & Coefficient & SE & $\mathrm{t}$-value & P-value & $95 \% \mathrm{CI}$ of intercept \\
\hline \multicolumn{6}{|c|}{ C677T for cervical cancer } \\
\hline TT vs. CC & 5.480 & 4.639 & 1.18 & 0.268 & (-5.015 to 15.976$)$ \\
\hline TT+CT vs. CC & -1.352 & 2.836 & -0.48 & 0.645 & $(-7.766$ to 5.063$)$ \\
\hline TT vs. CT+CC & 0.948 & 1.621 & 0.58 & 0.573 & $(-2.720$ to 4.616$)$ \\
\hline \multicolumn{6}{|c|}{ C677T for CIN II/III } \\
\hline TT vs. CC & -1.978 & 2.113 & -0.94 & 0.418 & (-8.701 to 4.746$)$ \\
\hline TT+CT vs. CC & 13.775 & 8.494 & 1.62 & 0.180 & $(-9.807$ to 37.358$)$ \\
\hline TT vs. CT+CC & 0.427 & 1.846 & 0.23 & 0.832 & $(-5.448$ to 6.302$)$ \\
\hline \multicolumn{6}{|c|}{ A1298C for cervical cancer } \\
\hline CC vs. AA & -0.867 & 1.051 & -0.92 & 0.385 & (-3.393 to 1.459$)$ \\
\hline $\mathrm{CC}+\mathrm{CA}$ vs. AA & 6.484 & 4.034 & 1.61 & 0.206 & (-6.355 to 19.323$)$ \\
\hline $\mathrm{CC}$ vs. $\mathrm{CA}+\mathrm{AA}$ & -2.077 & 1.541 & -1.35 & 0.271 & (-6.980 to 2.828$)$ \\
\hline
\end{tabular}

CI, confidence interval; CIN, cervical intraepithelial neoplasia; MTHFR, methylenetetrahydrofolate reductase.

other populations $(3,9,11,23,24,35)$. Similarly, the influence of MS A2756G polymorphism on the susceptibility of cervical tumorigenesis also remains controversial $(11,15,23)$. Therefore, a systematic meta-analysis with regard to the three most investigated polymorphisms of MTHFR (C677T and A1298C) and MS (A2756G) genes is needed in order to determine the influence of MTHFR or MS polymorphisms on susceptibility to $\mathrm{CIN}$ II/III or cervical cancer.

A total of 13 studies with 1,936 cases and 2,858 controls were identified for the investigation of MTHFR C677T and A1298C polymorphisms, while 3 studies with 389 cases and 440 controls were eligible for the investigation of MS A2756G polymorphism in the present study. No significant associations were found in the worldwide population between polymorphisms of the MTHFR gene (C677T and A1298C) or the MS gene (A2756G), and CIN II/III or cervical cancer. However, stratified analysis by ethnicity demonstrated that increased susceptibility was restricted to Asian females when homozygous and recessive genetic model contrasts were conducted. By contrast, an inverse association of the MTHFR C677T polymorphism and cervical cancer was observed in Caucasian females. It has been established that one-carbon metabolism may be affected not only by genes encoding enzymes involved in this pathway, but also by dietary factors such as folate, vitamin B and alcohol intake (36). A previous study demonstrated that the MTHFR TT genotype constitutes a protective factor against susceptibility to colorectal cancer in folate-replete subjects, while this genotype conferred an enhanced risk of colorectal cancer in combination with a folate-deficient status (37). Therefore, the dipartite results of the effects of MTHFR C677T polymorphism between Asian and Caucasian females in the present study may be due to the higher folate intake in North America and Europe in dietary supplement use and food fortification (38). This may also be due to ethnic differences in additional genetic factors and different environments. No associations were found between MTHFR A1298C or MS A2756G gene polymorphisms and cervical cancer in the different ethnic groups partially due to the fact that each of these single gene variations do not appear to affect the function of MTHFR or MS by itself until it is heterozygous with other gene polymorphisms on the same sequence.

The sensitivity analysis in the present study indicated that the summary estimate of effect of MTHFR C677T, MTHFR A1298C and MS A2756G polymorphisms on the risk of cervical cancer and CIN II/III was robust, and was not significantly altered following various comparisons. Moreover, the evaluation of publication bias in the present study did not indicate the existence of such bias towards the observed association between MTHFR C677T or A1298C variant and the risk for CIN II/III or cervical cancer in the comparison of variant alleles, suggesting that the results were credible and stable.

However, there are several limitations that may limit the strength of the conclusions. Firstly, the statistical power of the meta-analysis is relatively low, due to the fact that the number of cases of many of the included studies was relatively small and the fact that the controls were not defined uniformly and were not representative enough $(1,13,24)$. Secondly, different racial distributions and genetic heterogeneity existed among the studied populations, which resulted in conflicting results and led to the inability to examine the potential susceptibility of MTHFR or MS polymorphisms $(23,39)$. Thirdly, the present study focused only on the three most investigated SNPs associated with CIN II/III or cervical cancer due to the limited number of informative studies. Fourthly, most data were not stratified according to the investigated SNPs by behavioral and environmental cofactors, such as dietary folate intake, folate and other micronutrient status within the body, HPV infection, hormone or oral contraceptives, smoking, which might make it difficult to investigate the joint effects among pairs of variables modifying the susceptibility of cervical cancer or precancerous conditions. Moreover, variations in laboratory procedures, such as methods of data collection and genotyping, could also explain the inconsistent results. Therefore, a more precise analysis needs to be performed upon availability of data from additional investigations with an improved design.

In conclusion, the present meta-analysis supports the hypothesis that the MTHFR 677TT polymorphism is associ- 
ated with an increased risk of cervical cancer in Asian females, while an inverse association applies to Caucasian females. Meanwhile, no association was detected between the MTHFR C677T polymorphism and susceptibility to CIN II/III overall or in ethnically defined populations. Similarly, MTHFR A1298C and MS A2756G polymorphisms did not appear to be associated with overall cervical cancer risk or in ethnically defined populations. Larger population-based surveys concerning gene-gene, gene-nutrients and gene-behavioral risk factors interactions in a specific population are needed to further determine the role of MTHFR and MS gene polymorphisms in the risk of cervical cancer.

\section{References}

1. Piyathilake CJ, Macaluso M, Johanning GL, Whiteside M, Heimburger DC and Giuliano A: Methylenetetrahydrofolate reductase (MTHFR) polymorphism increases the risk of cervical intraepithelial neoplasia. Anticancer Res 20: 1751$1757,2000$.

2. Jemal A, Bray F, Center MM, Ferlay J, Ward E and Forman D: Global cancer statistics. CA Cancer J Clin 61: 69-90, 2011.

3. Kohaar I, Kumar J, Thakur N, et al: Homocysteine levels are associated with cervical cancer independent of methylene tetrahydrofolate reductase gene (MTHFR) polymorphisms in Indian population. Biomarkers 15: 61-68, 2010.

4. Kohaar I, Thakur N, Salhan S, et al: TNFa-308G/A polymorphism as a risk factor for HPV-associated cervical cancer in Indian population. Cell Oncol 29: 249-256, 2007.

5. García-Closas R, Castellsagué X, Bosch X and González CA: The role of diet and nutrition in cervical carcinogenesis: a review of recent evidence. Int J Cancer 117: 629-637, 2005.

6. Tong SY, Kim MK, Lee JK, et al: Common polymorphisms in methylenetetrahydrofolate reductase gene are associated with risks of cervical intraepithelial neoplasia and cervical cancer in women with low serum folate and vitamin B12. Cancer Causes Control 22: 63-72, 2011

7. Kjellberg L, Hallmans G, Ahren AM, et al: Smoking, diet, pregnancy and oral contraceptive use as risk factors for cervical intra-epithelial neoplasia in relation to human papillomavirus infection. Br J Cancer 82: 1332-1338, 2000.

8. Josefsson AM, Magnusson PK, Ylitalo N, et al: Viral load of human papilloma virus 16 as a determinant for development of cervical carcinoma in situ: a nested case-control study. Lancet 355: 2189-2193, 2000.

9. Gerhard DS, Nguyen LT, Zhang ZY, Borecki IB, Coleman BI and Rader JS: A relationship between methylenetetrahydrofolate reductase variants and the development of invasive cervical cancer. Gynecol Oncol 90: 560-565, 2003.

10. Yamada K, Chen Z, Rozen R and Matthews RG: Effects of common polymorphisms on the properties of recombinant human methylenetetrahydrofolate reductase. Proc Natl Acad Sci USA 98: 14853-14858, 2001.

11. Tong SY, Lee JM, Song ES, et al: The effects of polymorphisms in methylenetetrahydrofolate reductase (MTHFR), methionine synthase (MTR), and methionine synthase reductase (MTRR) on the risk of cervical intraepithelial neoplasia and cervical cancer in Korean women. Cancer Causes Control 21: 23-30, 2010.

12. Prasad VV and Wilkhoo H: Association of the functional polymorphism C677T in the methylenetetrahydrofolate reductase gene with colorectal, thyroid, breast, ovarian, and cervical cancers. Onkologie 34: 422-426, 2011.

13. Goodman MT, McDuffie K, Hernandez B, et al: Association of methylenetetrahydrofolate reductase polymorphism C677T and dietary folate with the risk of cervical dysplasia. Cancer Epidemiol Biomarkers Prev 10: 1275-1280, 2001.

14. Parkin DM, Bray F, Ferlay J and Pisani P: Global cancer statistics, 2002. CA Cancer J Clin 55: 74-108, 2005.

15. Kang S, Kim JW, Kang GH, Park NH, Song YS, Kang SB and Lee HP: Polymorphism in folate- and methionine-metabolizing enzyme and aberrant $\mathrm{CpG}$ island hypermethylation in uterine cervical cancer. Gynecol Oncol 96: 173-180, 2005.

16. Powers HJ: Interaction among folate, riboflavin, genotype, and cancer, with reference to colorectal and cervical cancer. J Nutr 135 (Suppl 12): S2960-S2966, 2005.
17. Zoodsma M, Nolte IM, Schipper M, et al: Methylenetetrahydrofolate reductase (MTHFR) and susceptibility for (pre)neoplastic cervical disease. Hum Genet 116: 247-254, 2005.

18. Hazra A, Wu K, Kraft P, Fuchs CS, Giovannucci EL and Hunter DJ: Twenty-four non-synonymous polymorphisms in the one-carbon metabolic pathway and risk of colorectal adenoma in the Nurses' Health Study. Carcinogenesis 28: 1510-1519, 2007.

19. Stroup DF, Berlin JA, Morton SC, et al: Meta-analysis of observational studies in epidemiology: a proposal for reporting. Meta-analysis Of Observational Studies in Epidemiology (MOOSE) group. JAMA 283: 2008-2012, 2000.

20. Qi X, Ma X, Yang X, et al: Methylenetetrahydrofolate reductase polymorphisms and breast cancer risk: a meta-analysis from 41 studies with 16,480 cases and 22,388 controls. Breast Cancer Res Treat 123: 499-506, 2010.

21. Sull JW, Jee SH, Yi S, et al: The effect of methylenetetrahydrofolate reductase polymorphism C677T on cervical cancer in Korean women. Gynecol Oncol 95: 557-563, 2004.

22. Shekari M, Sobti RC, Kordi Tamandani DM, et al: Impact of methylenetetrahydrofolate reductase (MTHFR) codon (677) and methionine synthase (MS) codon (2756) on risk of cervical carcinogenesis in North Indian population. Arch Gynecol Obstet 278: 517-524, 2008.

23. Mostowska A, Myka M,Lianeri M, Roszak A and Jagodziński PP: Folate and choline metabolism gene variants and development of uterine cervical carcinoma. Clin Biochem 44: 596-600, 2011.

24. Lambropoulos AF, Agorastos T, Foka ZJ, Chrisafi S, Constantinidis TC, Bontis J and Kotsis A: Methylenetetrahydrofolate reductase polymorphism C677T is not associated to the risk of cervical dysplasia. Cancer Lett 191: 187-191, 2003.

25. Delgado-Enciso I, Martínez-Garza SG, Rojas-Martínez A, et al: The effect of MTHFR polymorphisms, pregnancy and first intercourse on cervical cancer in a population from the Northeastern Mexico. Rev Invest Clin 58: 462-469, 2006 (In Spanish).

26. Piyathilake CJ, Azrad M, Macaluso M, Johanning GL, Cornwell PE, Partridge EE and Heimburger DC: Protective association of MTHFR polymorphism on cervical intraepithelial neoplasia is modified by riboflavin status. Nutrition 23: 229-235, 2007.

27. Wang JT, Ma XC, Cheng YY, Ding L and Zhou Q: A case-control study on the association between folate and cervical cancer. Zhonghua Liu Xing Bing Xue Za Zhi 27: 424-427, 2006 (In Chinese)

28. Agodi A, Barchitta M, Cipresso R, et al. Distribution of p53, GST, and MTHFR polymorphisms and risk of cervical intraepithelial lesions in sicily. Int J Gynecol Cancer 20: 141-146, 2010.

29. Muñoz N, Bosch FX, de Sanjosé S, et al; International Agency for Research on Cancer Multicenter Cervical Cancer Study Group: Epidemiologic classification of human papillomavirus types associated with cervical cancer. N Engl J Med 348: 518-527, 2003.

30. Hemminki K, Dong C and Vaittinen P: Familial risks in cervical cancer: is there a hereditary component? Int J Cancer 82: 775-781, 1999.

31. Blount BC, Mack MM, Wehr CM, et al: Folate deficiency causes uracil misincorporation into human DNA and chromosome breakage: implications for cancer and neuronal damage. Proc Natl Acad Sci USA 94: 3290-3295, 1997.

32. Esteller M and Herman JG: Cancer as an epigenetic disease: DNA methylation and chromatin alterations in human tumours. J Pathol 196: 1-7, 2002.

33. Fowler BM, Giuliano AR, Piyathilake C, Nour M and Hatch K: Hypomethylation in cervical tissue: is there a correlation with folate status? Cancer Epidemiol Biomarkers Prev 7: 901-906, 1998.

34. Weisberg I, Tran P, Christensen B, Sibani S and Rozen R: A second genetic polymorphism in methylenetetrahydrofolate reductase (MTHFR) associated with decreased enzyme activity. Mol Genet Metab 64: 169-172, 1998.

35. Rao GG, Kurien A, Gossett D, Griffith WF, Coleman RL and Muller CY: A case-control study of methylenetetrahydrofolate reductase polymorphisms in cervical carcinogenesis. Gynecol Oncol 101: 250-254, 2006.

36. Hubner RA and Houlston RS: MTHFR C677T and colorectal cancer risk: a meta-analysis of 25 populations. Int J Cancer 120: 1027-1035, 2007.

37. Chen J, Giovannucci E, Kelsey K, et al: A methylenetetrahydrofolate reductase polymorphism and the risk of colorectal cancer. Cancer Res 56: 4862-4864, 1996.

38. Hankey GJ and Eikelboom JW: Homocysteine and stroke. Lancet 365: 194-196, 2005.

39. Magnusson PK, Sparén P and Gyllensten UB: Genetic link to cervical tumours. Nature 400: 29-30, 1999. 